\title{
Moderate Survival after Reirradiation
}

National Cancer Institute

\section{Source}

National Cancer Institute. Moderate Survival after Reirradiation. NCI Thesaurus. Code C127866.

A score of 2 on the Combs Prognostic Index scale. 